\title{
Modeling, Simulation, and Analysis of Auto Warming Up and Overheat Prevention System in Komatsu Hydraulic Excavator PC 200-8
}

\author{
${ }^{1,2}$ Sri Sadono \\ ${ }^{1}$ United Tractors, Cakung - Indonesia \\ ${ }^{2}$ Master of Mechanical Engineering \\ Swiss German University \\ Tangerang City, Indonesia \\ sris@unitedtractors.com \\ Henry Nasution \\ Master of Mechanical Engineering \\ Swiss German University \\ Tangerang City, Indonesia \\ henry.nasution@sgu.ac.id
}

\author{
${ }^{2,3}$ Cuk Supriyadi Ali N \\ ${ }^{3}$ Agency for the Assessment \& Application \\ of Technology (BPPT) \\ Tangerang, Indonesia \\ ${ }^{2}$ Master of Mechanical Engineering \\ Swiss German University \\ Tangerang City, Indonesia \\ cuksupriyadi@gmail.com
}

\author{
*Dena Hendriana \\ Master of Mechanical Engineering \\ Swiss German University \\ Tangerang City, Indonesia \\ dena.hendriana@sgu.ac.id
}

Gembong Baskoro

Master of Mechanical Engineering

Swiss German University

Tangerang City, Indonesia

gembong.baskoro@sgu.ac.id

\begin{abstract}
Komatsu PC 200-8 hydraulic excavator is one of the most popular heavy equipment machine models, widely used in general sectors: construction, agriculture, and plantation. This excavator is equipped with electrical system, hydraulic system, and mechatronic system. All actuator movement in this excavator are controlled by mechatronic system. High skilled mechanics are needed to maintain the mechatronic system in this excavator. Good training method is needed to produce a skillful mechanic. The training method is conducted by theoretical introduction of the mechatronic system and followed by practice in laboratories, workshops, as well as in the field. In this project, mechatronic system simulator for Komatsu hydraulic excavator is developed to simulate auto warming up and overheat prevention system for the training purpose. The simulator has been tested in training and based on interviews with trainees, the simulator can help the learning process in the training and improve trainee knowledge and understand to operate and maintain the control system on hydraulic excavator.
\end{abstract}

Keywords-hydraulic excavator, simulator, mechatronics, engine, auto warming up, overheat prevention system.

\section{INTRODUCTION}

Hydraulic excavator in Fig. 1 is generally used for digging soil, pouring soil into a dump truck, making a trench, levelling land, clearing tree roots, breaking stones, harvesting forest, etc. The use of hydraulic excavator is very wide, and it can be used in mining sector, plantation sector and forestry, and in the construction sector [1]. The hydraulic excavator system is using mechatronics equipment system, consisting three important parts. The first part is input part consisting of sensors and switches, second part is controller that processes the input data into a command, and third part is actuator that executes the command into movements.

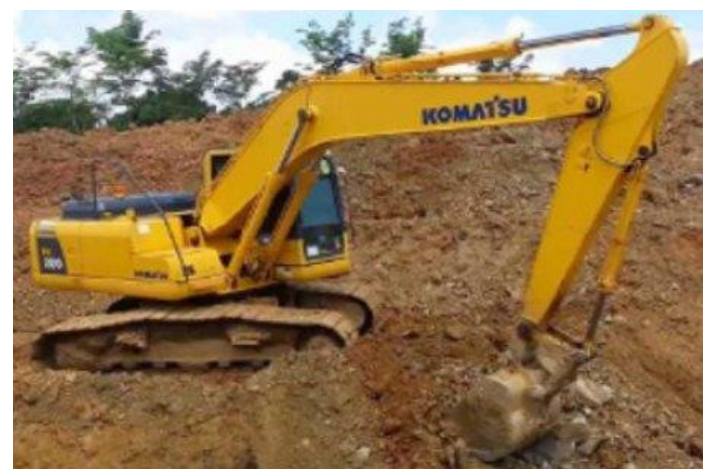

Fig. 1. Komatsu hydraulic excavator PC 200-8.

To maintain the performance of the mechatronic system is very important for the reliability of the excavator. UT School as a training institution under the Karya Bakti United Tractors Foundation is given the task to train the mechanics to perform maintenance and repair of heavy equipment, especially hydraulic excavators. Simulator is used to facilitate learning process in the training class. The simulator is used for learning practice in the classroom and workshops before using actual hydraulic excavator units during the field practice and on the job training.

The Objectives of this work are

- To develop simulator for describing and analyzing auto warming up and overheat prevention system on hydraulic excavator Komatsu PC 200-8.

- To facilitate the learning process of electric control system in hydraulic excavator.

- To improve the effectiveness of learning process of the electrical control system. 
Based on Marzano and Kendall [2] theory in a new learning taxonomy, psychomotor competencies are developed by the process of learning skills which include basic, combinations and complex combinations of trainings. The training combination is conducted by theory in the classroom and by practice in workshops, while the training complex combinations is conducted on the job training.

Hung and Lin [3] explained that using a simulator or modelling can improve the efficiency of teaching process in the classroom. They also recommended to provide more learning examples to ease the students learning process. Learning by seeing is very effective process as Eldirdiry [4] stated that the biped robot has been proven to mimic the various phases of human gait. Also, Gupta [5] used a Simulink model to perform a signal benchmarking of the vehicle test.

\section{LITERATURE REVIEW \& RESEARCH METHODOLOGY}

\section{A. Mechatronics System on Heavy Equipment}

Nowadays all heavy equipment is using mechatronic system to control actuators. There are five main components in mechatronics system: sensors, controllers, actuators, monitors, and wire harness. Mechanics must study those mechatronics system components.

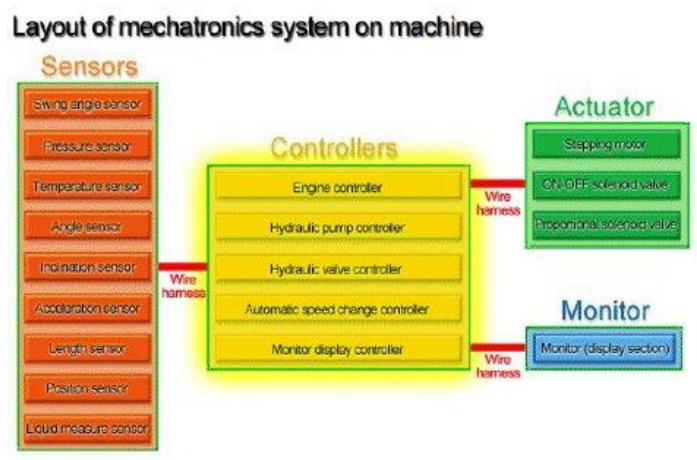

Fig. 2. Layout of mechatronics system on machine of heavy equipment.

Layout of mechatronics system in hydraulic excavator Komatsu PC 200-8 is shown in Fig. 2. There are 9 functionalities of mechatronic systems in the Komatsu hydraulic Excavator PC 200-8: 1) Engine and pump composite control function. 2) Pump and valve control function. 3) Power maximizing function. 4) Autodeceleration function. 5) Auto-warm-up and overheat prevention function. 6) Swing control function. 7) Travel control function. 8) Attachment flow control circuit selector function (if equipped). 9) Monitor system.

In this study, the discussion was limited to the auto warming-up and overheat prevention system as shown in Fig. 3.

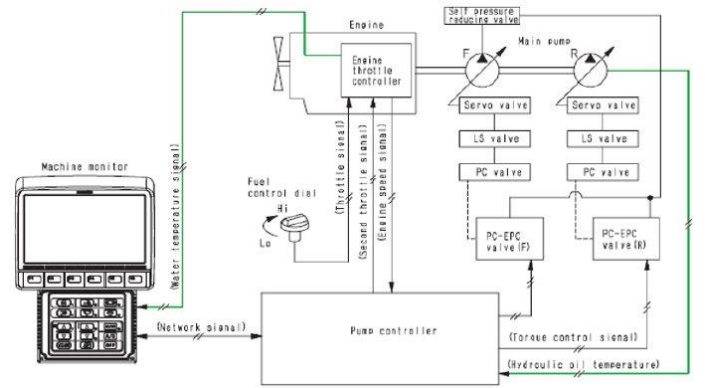

Fig. 3. Diagram of auto warming up and overheat prevention systems in komatsu hydraulic excavator PC200-8.

The Auto warming-up function system on the Komatsu PC200-8 hydraulic excavator works by increasing engine RPM when the coolant temperature is too low [6]. The Overheat prevention function system works by reducing the hydraulic pump load when the coolant temperature or hydraulic oil is too high exceeding the standard temperature during operation.

In addition to discussing the main functions of auto warming up and overheat prevention function, we must also understand the function of engine rotation control as shown in Fig. 4.

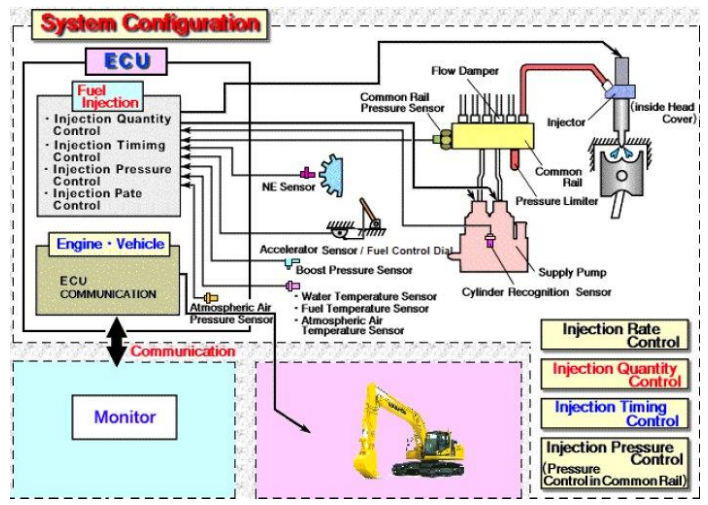

Fig. 4. Fuel control system to control engine rotation in komatsu PC200-8.

In this study, the simulator is design to show how the auto warming up and overheat Prevention Function systems work. The simulator is built using the Arduino Mega 2560, with simulated inputs and outputs according to the PC200-8 working system on the actual system. Arduino was also used for monitoring and automatic switching fuel filters in the Komatsu excavator [7]. The diagram of the simulator is shown in Fig. 5 [8-14]. The problem limitations on this study are: 1) Parameter measurements such as voltage, current, resistance, sensor output, input are done on the Komatsu hydraulic excavator PC 200-8 and compared with the measurements done on the simulator. 2) Evaluation for the application of the simulator is done on users from UT School students and instructors.

\section{B. Research Methodology}

The research was conducted to create a simulator according to the working system in the real hydraulic 
excavator unit. The research begins by determining the problems that exist in our training class due to the absence of a simulator. Then literature review was done to learn from other researchers in solving similar problems. Simulator was then designed to mimic the real Komatsu PC200-8 hydraulic excavator auto warming-up and overheat prevention systems. The simulator can produce data that students can use for analysis.

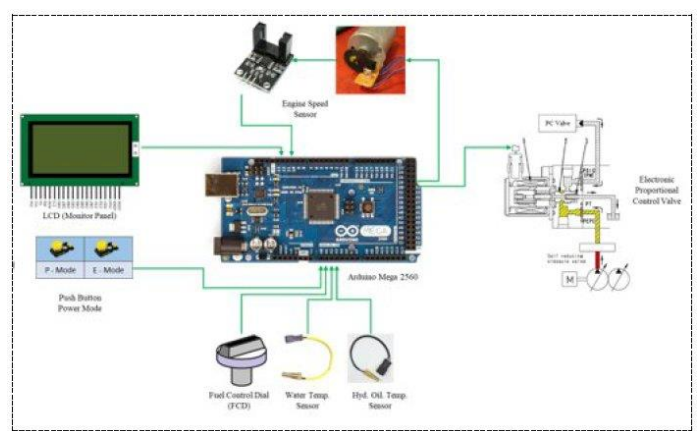

Fig. 5. Diagram of Arduino Mega 2560 for Komatsu hydraulic excavator PC200-8 simulator.

\section{Simulator Flow and Wiring Diagram}

Wiring diagram of the simulator using Arduino Mega 2560 in Proteus 8 program is shown in Fig. 6.

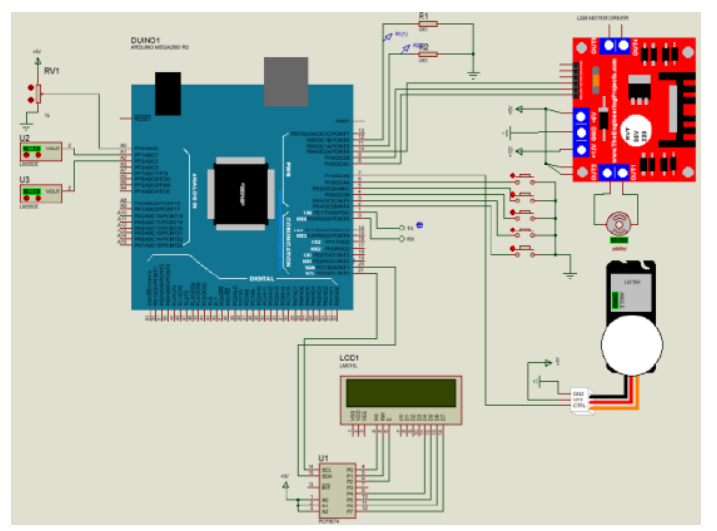

Fig. 6. Diagram of simulator for auto warming-up and overheat prevention systems in proteus 8 program.

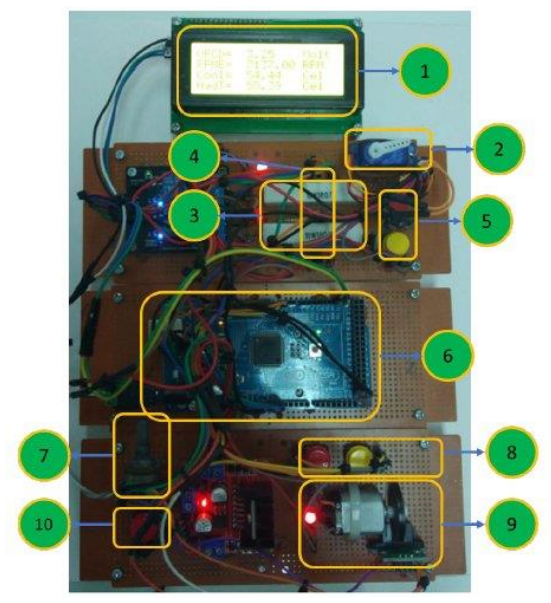

Fig. 7. Completed simulator on PCB board.
Completed simulator using PCB Board according to schematic diagram is shown in Fig. 7. The flow diagram of the simulator is shown in Fig. 8.

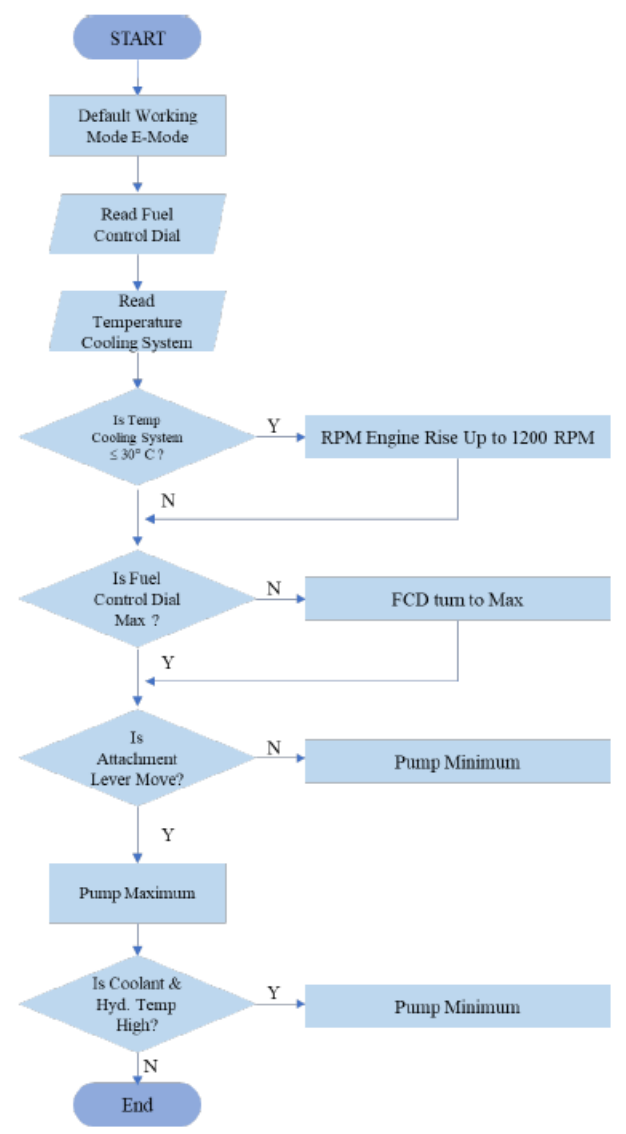

Fig. 8. Completed flow chart simulator for auto warming up \& overheat prevention systems in hydraulic excavator komatsu PC200-8.

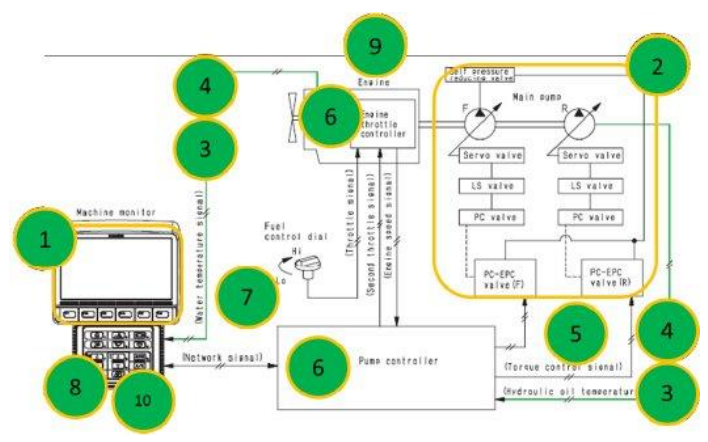

Fig. 9. Completed schematic diagram of auto warming up and overheat prevention system hydraulic excavator komatsu PC 200-8.

Schematic diagram of auto warming-up and overheating prevention system is shown in Fig. 9 and component names in the diagram: 1) Monitor panel. 2) Servo motor (simulation of servo valve hydraulic pump). 3) Engine and hydraulics system. 4) Cooling and hydraulic temperature sensor. 5) Push button for normal attachment and relief. 6) Engine and pump controller. 7) Fuel control dial. 8) Power mode P \& E button. 9) Engine speed simulator. 10) Engine stops push button. 


\section{RESULTS}

Fig. 10 shows the comparison of the simulator results with the actual measurements in the real machine. The measurements are done to simulate the functions of auto warming up and overheat prevention systems, namely: 1) Output voltage on fuel control dial. 2) Engine rotation. 3) Auto warming up function. 4) Engine cooling overheat prevention system function. 5) Hydraulic overheat prevention system function. 6) Hydraulic pump regulation system function.
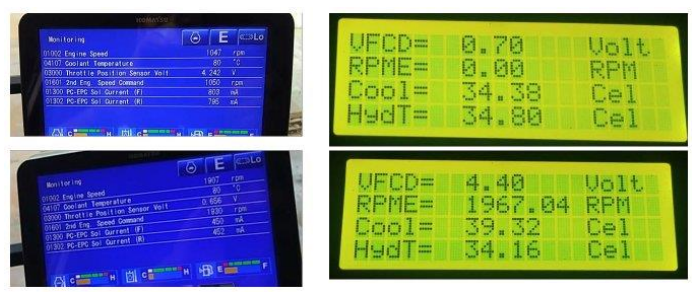

Fig. 10. Comparison of monitoring panel from the actual monitor panel and the simulator.

\section{A. Comparison of Output Voltages from simulators and} Actual Unit.

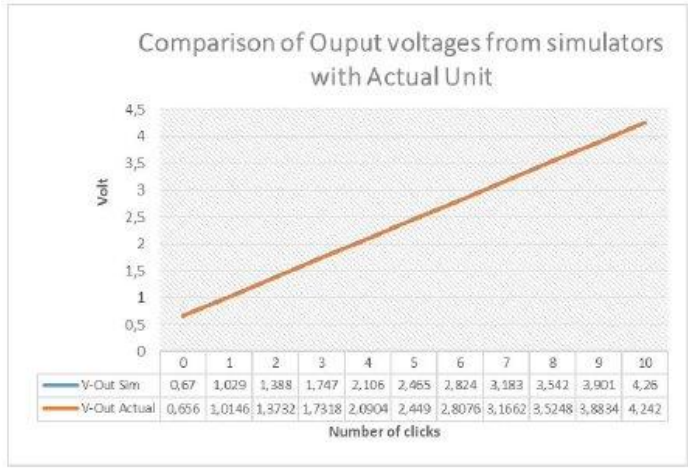

Fig. 11. Comparison of output voltages from actual unit monitor panel and the simulator.

Fig. 11 shows the comparison data of the output voltage from the simulator with the actual voltage on the Komatsu 200-8 hydraulic excavator unit. The voltage difference is only around $0.014 \mathrm{~V}$. The simulator output voltage starts from $0.67 \mathrm{~V}$ whereas the actual unit starts from $0.656 \mathrm{~V}$ and the simulator maximal output is $4.26 \mathrm{~V}$ whereas the actual unit is $4.242 \mathrm{~V}$.

\section{B. Comparison of Output Rotation Per Minutes (RPM) from simulators and Actual Unit.}

Fig.12 shows the simulation of engine round speed, in rotations per minute. Simulator data starts from 1042 RPM for minimum engine rotation output while the actual Komatsu hydraulic excavators PC200-8 starts from 1046 RPM, so the difference is 4 RPM. For the maximum engine rotation speed, the simulator gives 1915 RPM while the actual engine gives 1907 RPM, so the difference is 8 RPM.

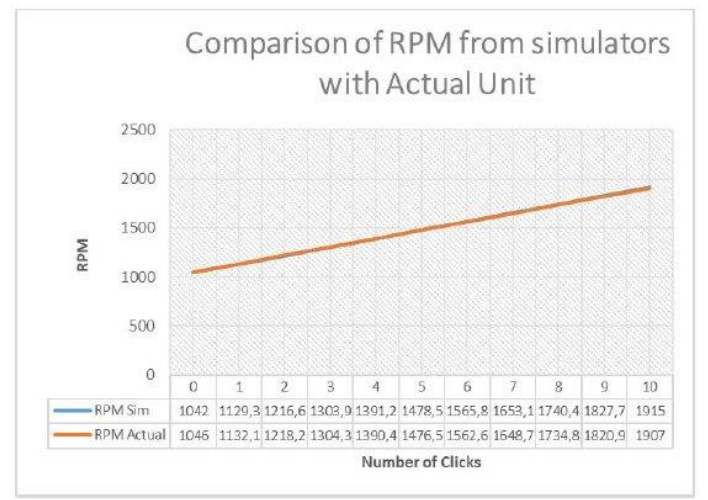

Fig. 12. Comparison of engine rotation speed in RPM between actual unit and the simulator.

\section{Comparison of Auto warming Up Function from Simulator with Actual Unit}

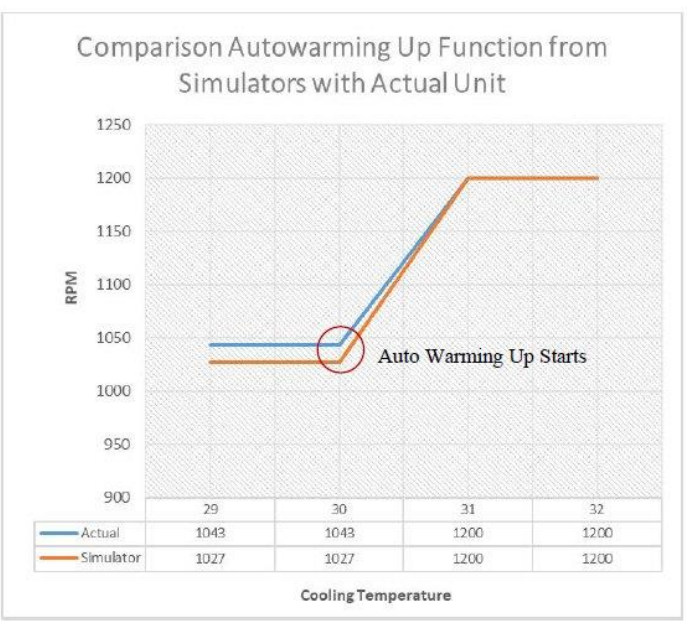

Fig. 13. Comparison in auto warming-up function in actual unit and simulator.

The function of auto warming up system of simulator is shown in Fig. 13. The coolant temperature in the cooling system below or equal to $30^{\circ} \mathrm{C}$ will raise the engine RPM from 1027 to 1200 RPM. In the actual machine, the coolant temperature below or equal to $30^{\circ} \mathrm{C}$ raised the engine RPM from 1043 to 1200 RPM.

\section{Comparison of Engine Cooling Overheat Prevention Function from Simulator and Actual Unit}

Setting point for overheat prevention system for cooling system is $100^{\circ} \mathrm{C}$. Fig. 14 shows that the simulator works well according to the function system.

\section{E. Comparison of Hydraulic Overheat Prevention Function from Simulator and Actual Unit}

Fig. 15 shows that the setting point of overheat prevention system for Hydraulic system is $95^{\circ} \mathrm{C}$ and the simulator works very well according to the function system. 


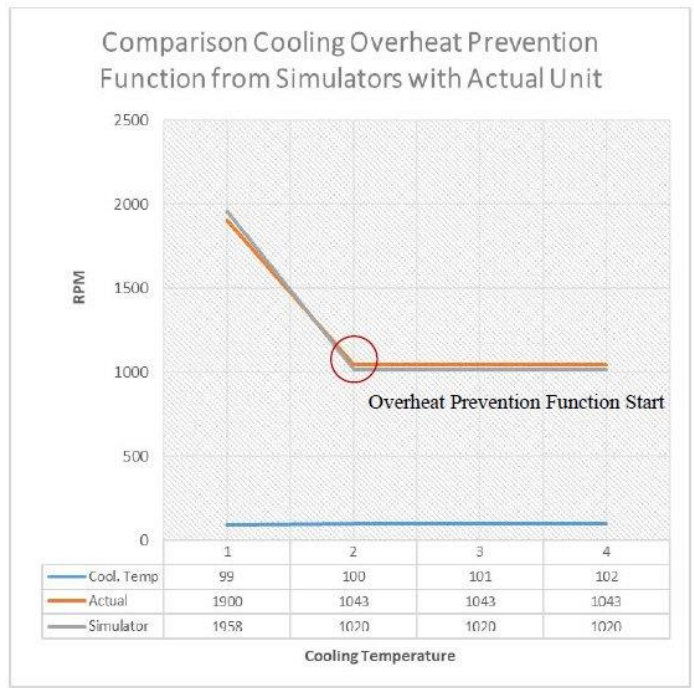

Fig. 14. Comparison of overheat prevention function system of cooling system from simulator and actual unit.

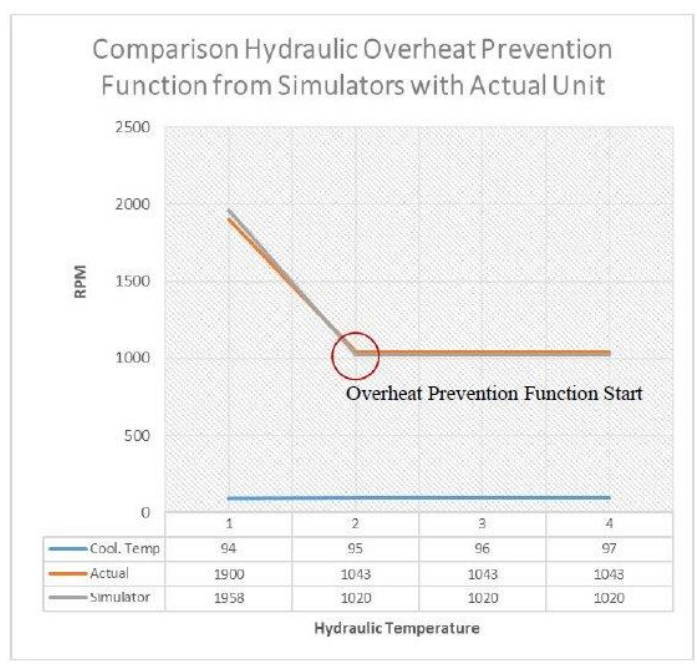

Fig. 15. Comparison of overheat prevention function system for hydraulic system for simulator and actual unit.

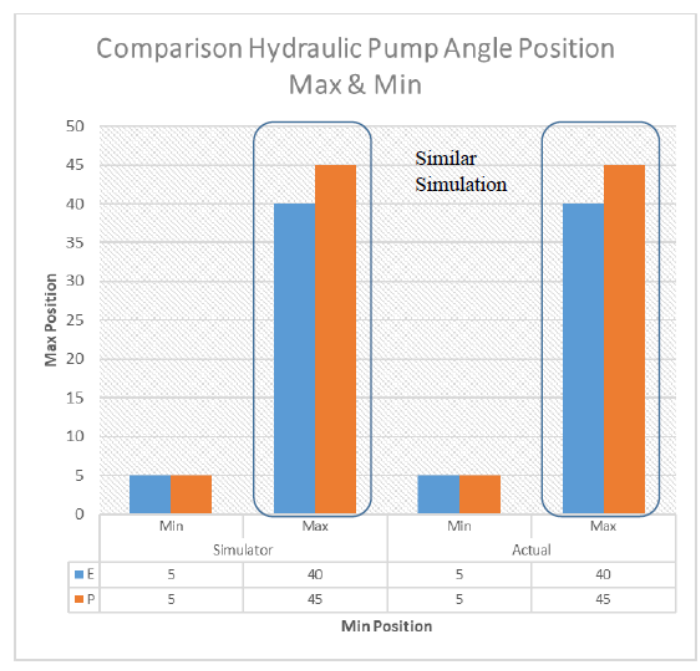

Fig. 16. Comparison of pump position in Max or Min condition.

\section{F. Comparison of Hydraulic Pump Angle Position Maximum \& Minimum Function from Simulator and Actual Unit}

Hydraulic pump setting is simulated using dc motor servo in $40^{\circ}$ and $45^{\circ}$ angle setting and it works properly comparable to actual unit as shown in Fig. 16. Small differences occur between simulator and actual unit due to different PWM to Voltage signal conversion from $\mathrm{dc}$ motor servo.

\section{G. Socialization of theSimulator}

Fig. 17 shows socialization of the Simulator in the forum of UT School instructor by online media via Microsoft Team. Feedbacks from the instructor are:

- Need to be developed into a board simulator.

- Need to add labels for the simulator components.

- Need to be created guide book for Simulator.

- Can be developed for other simulators.

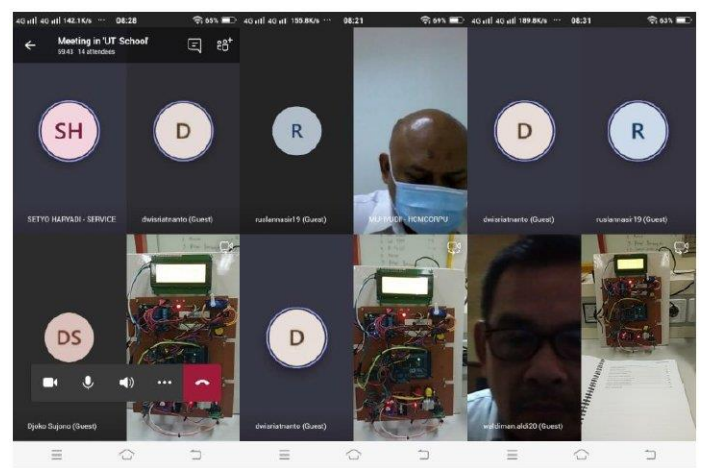

Fig. 17. Socialization of the simulator to UT School instructors.

The Simulator has been used in the training class by Online training via Zoom meeting as shown in Fig. 18. Feedbacks from the students are:

- Reorganize the cables. This suggestion will be done in the on-board simulator.

- Labels on the simulator components. This suggestion will be done in the on-board simulator.

- Students said that the on-board simulator is very useful and interesting to learn the electrical control system.

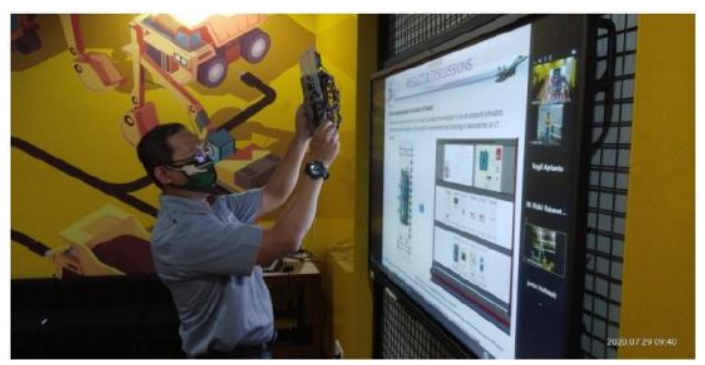

Fig. 18. Simulation for students UT School.

\section{H. Implementation of On-Board Simulator}

The simulator will be converted to on-board simulator as shown in Fig. 19 and the simulator will be used for development and teaching in laboratories at UT School. 


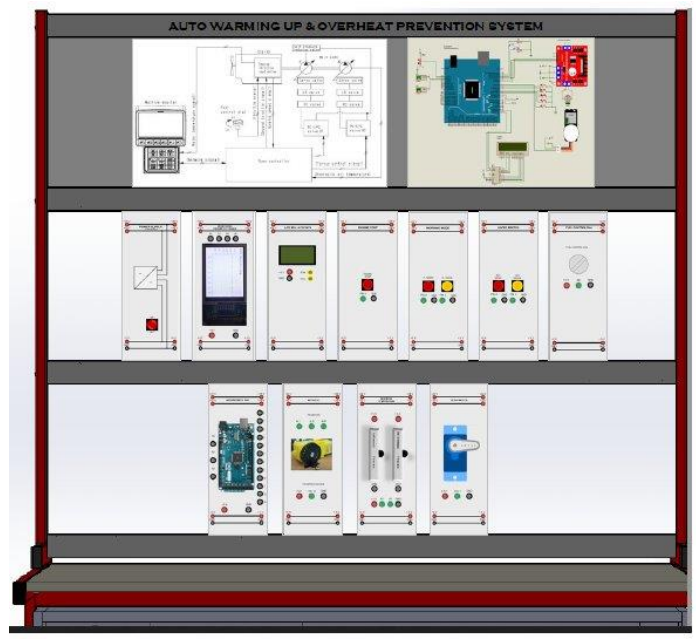

Fig. 19. Complete on board simulator design.

\section{CONCLUSIONS AND RECOMMENDATIONS}

\section{Conclusions}

- The simulator can provide simulations according to actual working conditions of auto warming up and overheat prevention systems.

- The simulator helps for better understanding on the principle of mechatronics on excavator PC200-8 as well as the inputs, outputs, process control.

\section{Recommendations}

Several recommendations for improving the simulator:

- User Interface of the simulator monitor panel needs to be upgraded to the actual panel monitor.

- The Push Button on the simulator panel monitor needs to be replaced with the lever of the actual unit.

\section{REFERENCES}

[1] UT School, Product Knowledge, unpublished.
[2] R. J. Marzano and J. S. Kendall, Praise for the Second Edition of the New Taxonomy of Educational Objectives, $2^{\text {nd }}$ ed., R. Livsey, Eds. Corwin Press: California. doi: 10.1016/B978-1-85617-8167.10013-X, 2007.

[3] J. F. Hung and J. C. Lin, "The development of the simulation modeling system and modeling ability evaluation", International Journal of U-\& E-Service, Science \& Technology, 2 (4), pp. 1-16, 2009.

[4] O. Eldirdiry, et al., "Modeling of a biped robot for investigating foot drop using MATLAB/Simulink," Simulation Modelling Practice and Theory, 98, p. 101972, 2020.

[5] R. Gupta, A Simulink Model for an Engine Cooling System and its Application for Fault Detection in Vehicles, University of Victoria, 2015.

[6] A. C. Komatsu, Manual PC200-8 PC200LC-8 PC220-8 PC22OLC-8 Hydraulic Excapator, 2006.

[7] G. Subekti, D. Hendriana, E. Sofyan, "Fuel filter data monitoring and auto switching at komatsu engine with arduino to improve life cycle time main fuel filter usage," $1^{\text {st }}$ Proceedings of The Conference on Management and Engineering in Industry (CMEI 2019), vol. 1, pp. 36-39, Tangerang, Indonesia, August 2019.

[8] "Ks0029 Keyestudio Digital Push Button," April 12, 2019 Accessed on: Nov 16, 2020 [Online]. Available: https://wiki.keyestudio.com/Ks0029_keyestudio_Digital_Push_But ton

[9] "DC Motor Crystal Clockwork," April 8, 2013. Accessed on: Nov 16, 2020 [Online]. Available: https://www.romanblack.com/onesec/DCmotor_xtal.htm

[10] "Sensor LM 35," October 2, 2018. Accessed on: Nov 16, 2020 [Online]. Available: https://mikrokontroler.mipa.ugm.ac.id/2018/10/02/sensor-lm-35/

[11] "Arduino Tutorial to Accsess L298N Motor Driver," August 27, 2017. Accessed on: Nov 16, 2020 [Online]. Available: https://www.nyebarilmu.com/tutorial-arduino-mengakses-drivermotor-1298n/

[12] "High Current Motor Driver H-Bridge Module IBT-2 using Arduino," September 26, 2016. Accessed on: Nov 16, 2020 [Online]. Available: http://www.labelektronika.com/2016/09/highcurrent-motor-driver-Ibt-2-arduino.html

[13] "L298 Motor Driver Library for Proteus," September 16, 2017. Accessed on: Nov 16, 2020 [Online]. Available: https://www.theengineeringprojects.com/2017/09/1298-motordriver-library-proteus.html

[14] T. Pan and Y. Zhu, Designing Embedded System with Arduino. Springer: Singpore, 2018, pp.3-12. 